\title{
Neuromuscular transmission in myasthenic single motor units
}

\author{
H. A. K A D R I E A N D W. F. B R O W N \\ From University Hospital, London, Ontario, Canada
}

SUM MARY In patients with myasthenia gravis neuromuscular transmission has been tested in individual hypothenar and thenar motor units using trains of near threshold electrical stimuli delivered to the motor nerve. The most important observations included: (1) the proportion of motor units with pathological decrements varied from 0 to $90 \%$, (2) the decrements in surface voltage were frequently much more normal in individual motor units than in the corresponding maximum compound potentials evoked by supramaximal nerve stimulation, and (3) the most abnormal decrements were observed in motor units at the low end of the surface voltage range. These observations can be interpreted to suggest important neurogenic factors in the pathogenesis of myasthenia gravis. An attractive alternative would be to suggest that the small motor units have the most abnormal neuromuscular transmission because they normally have a lower margin for safe neuromuscular transmission and, as a consequence, fail first in diseases of neuromuscular transmission.

Much has been learned recently about the basic pathophysiological mechanisms underlying myasthenia gravis (Satyamurti et al., 1975; Engel et al., 1976; Thornell et al., 1976; Elmqvist et al., 1977). This evidence has pointed to the postsynaptic receptor protein complex as the primary target in the disease. Experimental models have reproduced all the electrophysiological abnormalities, including post-tetanic potentiation that characterise the natural human disease.

Several important questions, however, remain.

1. Are all motor units (MUs) or neuromuscular junctions attacked at random in myasthenia gravis?

2. If not, what proportion of MUs have abnormal neuromuscular transmission?

3. If neuromuscular transmission abnormalities are observed in only a fraction of the total number of MUs, are the pathological motor units of one particular functional type?

4. Are the number of motor units in myasthenic muscle less than normal?

There has been no concerted attempt before this investigation to look at the proportions and functional types of motor units involved in

Address for reprint requests: Dr W. F. Brown, University Hospital, 339 Windermere Road, PO Box 5339, Postal Stn A, London, Ontario, Canada N6A 5A5.

Accepted 26 September 1977 myasthenic muscle. Neuromuscular transmission has been tested in occasional single motor units in response to trains of presynaptic stimuli (Desmedt and Borenstein, 1970). Certainly others have observed decrements in the voltage of single MUs recruited by muscle contraction (Lambert et al., 1961). The question of the number of MUs in myasthenic muscle has been a point of conflict, McComas et al. (1971) claiming a loss of MUs, and Ballantyne and Hansen (1974), using a computerised method, contending that the numbers were normal.

It was, therefore, of interest for us to investigate the above questions using the multiple point stimulation method (Kadrie et al., 1976) to test neuromuscular transmission (Kadrie and Brown, 1978) in myasthenia gravis and, in later communications, motor neurone disease and periphcral neuropathies.

We were also interested to find out if testing neuromuscular transmission in MUs was likely to be a better indicator of neuromuscular transmission failure than tests using supramaximal nerve stimulation. The latter can be uncomfortable and distorted by movement artefact, they require the testing of more than one muscle and, particularly for distal limb muscles. are often relatively insensitive (Slomiĉ et al., 1968; Desmedt and Borenstein, 1976; Ozdemir and Young, 1976). 
Muscles more frequently and severely involved such as the proximal limb, facial eyelid, and extraocular muscles are more difficult to test (Ozdemir and Young, 1976).

Our working hypothesis was that if neuromuscular transmission abnormalities are not equally expressed in all motor units, the unavoidable mix of unequally affected MUs in the maximum compound muscle potential will make tests using supramaximal stimulation less likely to be abnormal than tests at the level of the individual motor unit. This turned out to be correct. The methods provided an opportunity to investigate also the relationship of changes at single neuromuscular junctions, indicated by the single fibre EMG electrode, to changes in the MU acting as a unit, reflected in the surface voltage.

\section{Subjects and methods}

A total of eight myasthenic patients were tested in detail; two were over the age of 60 years. The clinical details of the eight cases are summarised in Table 1.

The electrophysiological methods have been outlined before (Kadrie et al., 1976; Kadrie and Brown, 1978). In this investigation, the objectives and measures included the following:

1. In myasthenic and control subjects to compare (a) maximum compound potential peak-topeak voltages (p-pV) both thenar and hypothenar, (b) median and ulnar nerve maximum conduction velocities, and (c) the range and distribution of MU potential p-pVs for both the thenar and hypothenar muscles.

2. To find the proportion of motor units in myasthenics that have abnormal p-pV decrements.

3. To measure the $\mathrm{p}-\mathrm{pV}$ of MUs that have the most abnormal decrements in surface voltage in response to repetitive stimulation.

4. Further characterisation of the probable MU size by relating the adjusted latency (or fibre conduction velocity) to the surface $\mathrm{p}-\mathrm{pV}$ of control and myasthenic MUs.

5. To what extent decrements in MU p-pV can be reversed by edrophonium chloride $(10 \mathrm{mg}$ intravenously).

6. Whether post-tetanic exhaustion and abnormal $\mathrm{p}-\mathrm{pV}$ decrements go hand in hand in the same MU.

7. To correlate single muscle fibre "jitter", changes in the interspike interval, and the presence or absence of muscle spike generation block to changes in the corresponding surface MU potential.

To avoid exhaustion of all MUs at the beginning of the experimental protocol, supramaximal nerve stimulation at stimulus intervals of less than one second was carried out last. Single MUs were tested only after the best position for the surface recording electrode was established using supramaximal nerve stimulation at less than one per second.

\section{Results}

MAXIMUM COMPOUND POTENTIAL

In myasthenic patients, the hypothenar muscle maximum compound potential p-pV (size) was less than in corresponding controls $(24.4 \pm 3.1 \mathrm{mV})$ but the difference was not significant (Table 2). In the median nerves the thenar maximum compound potentials were larger in the two control subjects than in the two myasthenic nerves tested. Significant differences were not observed between the residual latencies and maximum motor conduction velocities in control compared to myasthenic ulnar or median nerves.

The maximum decrement $(10.3 \%)$ in the $\mathrm{p}-\mathrm{pV}$ of thenar or hypothenar maximum compound potentials was observed at a stimulus interval of 0.3 second. In six of the 10 myasthenic nerves

Table 1 Clinical details of eight myasthenic patients studied

\begin{tabular}{|c|c|c|c|c|c|c|}
\hline \multirow{2}{*}{$\begin{array}{l}\text { Patient } \\
\text { Initial }\end{array}$} & \multirow{2}{*}{$(\operatorname{Sex})$} & \multirow[b]{2}{*}{ Age $(y r)$} & \multirow{2}{*}{$\begin{array}{l}\text { Duration of } \\
\text { illness }(y r s)\end{array}$} & \multicolumn{3}{|c|}{ Distribution of muscle fatiguability } \\
\hline & & & & $E O M-L i d$ & Bulbar & $\operatorname{Limb}$ \\
\hline B & (F) & 14 & 1.2 & 4. & $-i$ & + \\
\hline $\mathbf{W}$ & (F) & 22 & 4 & $+t$ & ++ & ++ \\
\hline O & (M) & 24 & 4 & + & - & - \\
\hline $\mathbf{P}$ & (M) & 27 & 5 & + & + & \pm \\
\hline $\mathbf{P}$ & (M) & 28 & 1 & -+ & ++ & ++ \\
\hline $\mathbf{P}$ & (M) & 50 & 3 & ++ & - & + \\
\hline $\mathbf{H}$ & (M) & 66 & 1 & ++ & $+t+$ & ++ \\
\hline $\mathbf{W}$ & (M) & 73 & 3 & $+t+$ & $+t+$ & +1 \\
\hline
\end{tabular}

Grading of weakness: + mild, ++ moderate +++ severe.

EOM-Lid = extraocular muscles or eyelid. 
Table 2 Hypothenar and thenar maximum compound potentials and motor unit potentials in myasthenic patients and control subjects

\begin{tabular}{|c|c|c|c|c|}
\hline & \multicolumn{2}{|c|}{$M C P p-p V(m V)$} & \multicolumn{2}{|c|}{$X M U p-p V(m V)$} \\
\hline & $H T$ & $T$ & $H T$ & $T$ \\
\hline Control subjects & $24.4 \pm 3.1$ & $\begin{array}{l}23.5 \\
28.3\end{array}$ & $0.065 \pm 0.083$ & $0.070 \pm 0.069$ \\
\hline $\mathbf{n}$ & 12 & 2 & 42 & 25 \\
\hline $\begin{array}{l}\text { Myasthenia } \\
\text { gravis } \\
\text { n }\end{array}$ & $\begin{array}{l}22.9 \pm 1.9 \\
8\end{array}$ & $\begin{array}{c}20.2 \\
20.5 \\
2\end{array}$ & $\begin{array}{l}0.061 \pm 0.064 \\
60\end{array}$ & $\begin{array}{l}0.100 \pm 0.103 \\
27\end{array}$ \\
\hline $\begin{array}{l}\text { Significance of } \\
\text { difference }\end{array}$ & NS & NS & NS & NS \\
\hline
\end{tabular}

Includes only first motor units recruited at each point of stimulation. $\mathrm{HT}=$ hypothenar muscles, $\mathrm{T}=$ thenar muscles, $\mathrm{p}-\mathrm{pV}=$ peak-to-peak voltage, $\mathbf{M C P}=$ maximum compound potential, $\mathrm{MU}=$ single motor unit potential, $\mathbf{N S}=$ not significant.

tested, the maximum p-pV decrement was less than $5 \%$. Much more obvious pathological decrements occurred in single MUs.

\section{SINGLE MOTOR UNITS}

In the hypothenar muscle group the range and distribution of MU p-pVs did not differ between control and myasthenic subjects (Fig. 1, Table 2). The histograms illustrated in Fig. 1 represent all MUs isolated at all stimulation points. No attempt was made to increase the number of larger MUs as in the case of the control MU population tested in the previous paper (Kadrie and Brown, 1978). Neuromuscular transmission was difficult to test, however, in the second or third MUs recruited because frequently an abnormal decrement in the first MU recruited precluded accurate measurement, by subtraction, of changes in the $\mathrm{p}-\mathrm{pV}$ or p-pD of MUs excited at higher stimulus intensities. The result was that neuromuscular transmission was not tested in MUs larger than $0.3 \mathrm{mV} \mathrm{p}-\mathrm{pV}$ in the myasthenics.

Caution must be exercised in comparing MU estimates because of the inherent errors in the techniques (Brown and Milner-Brown, 1976; Milner-Brown and Brown, 1976) but the fact that there was no significant difference in the maximum hypothenar compound potentials or mean MU potential p-pV between control and myasthenic subjects suggested that the MU numbers in this muscle group are normal in myasthenia gravis. In thenar MUs, from subjects less than 60 years of age, the mean myasthenic MU $(0.100 \pm 0.103 \mathrm{mV})$ was larger than the control mean MU $(0.07 \pm 0.069 \mathrm{mV}$, Table 2$)$. Hence, for the median nerve a loss of MUs must be considered possible though not established.

In view of the larger thenar myasthenic MU surface voltage it was important to look for other
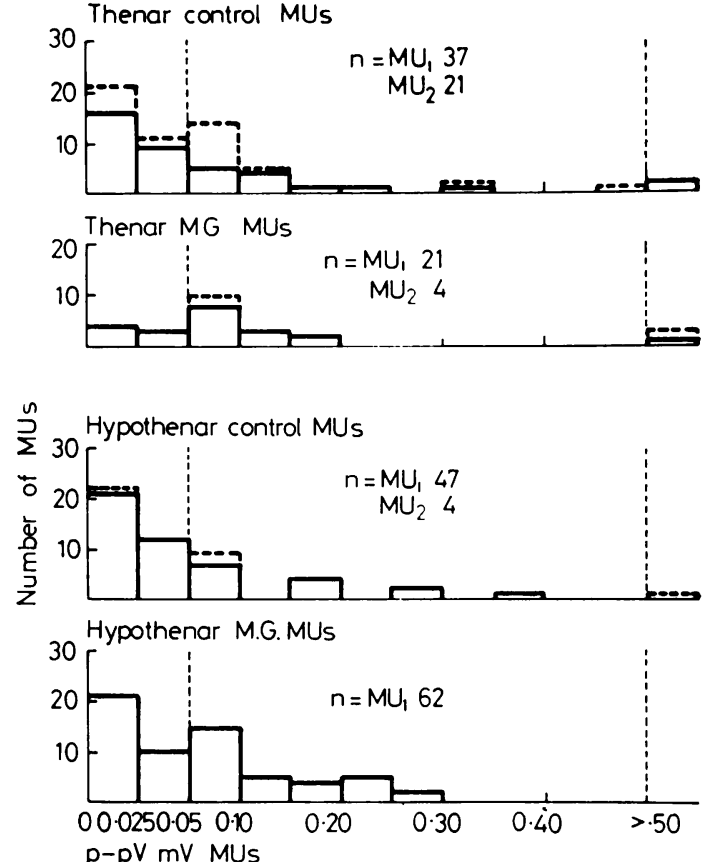

Fig. 1 Histograms of the size distribution of control and myasthenic MUs for patients under the age of 60 years. Motor units excited first at all points of stimulation have been labelled $M U_{1}$ (solid) and $M U s$ excited second in order by increments in the stimulus intensity have been labelled $M U_{2}$ (broken lines). The vertical dashed lines at $0.05 \mathrm{mV}$ emphasise the fact that the first two divisions on the abscissa are $0.025 \mathrm{mV}$, while later divisions are $0.05 \mathrm{mV}$. All MUs $>0.5 \mathrm{mV}$ have been grouped together. These histograms should be compared with the histograms in Fig. 2 of Kadrie et al., 1976.

physiological parameters that might indicate abnormalities in the function of the MU. Even though no significant difference was observed between the maximum motor conduction velocities in myasthenic compared with control median and ulnar nerves, a marginally significant $(P<0.02)$ difference was noted between the conduction velocities of single MUs from control median nerves $(49.8 \pm 8.6$ metres per second) and myasthenic MUs $(42.5 \pm 15 \mathrm{~m} / \mathrm{s})$. This difference is evident if comparison is made of the plots of $\mathrm{MU}$ p-pV against adjusted latency for control thenar MUs (Fig. 7 of Kadrie and Brown, 1978), to the corresponding plot for myasthenic MUs (Fig. 2). The larger mean MU surface voltage and lower MU impulse velocities, taken together, suggest possible neurogenic abnormalities in median motor nerve fibres. 


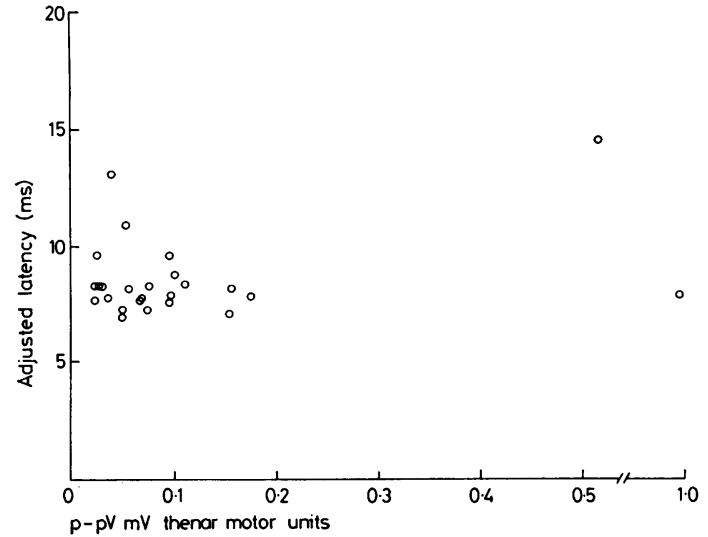

Fig. 2 Plot of the p-pV (in $m V$ ) of myasthenic thenar $M U s$ against the respective latencies (in $m s$ ) adjusted to the distance of $200 \mathrm{~mm}$ from the motor point. The adjusted latencies of the myasthenic thenar MUs are significantly longer than comparable controls (Fig. 11 of Kadrie and Brown, 1978).

In the ulnar nerve, however, no significant difference was observed, between hypothenar control $(43.8 \pm 13.9 \mathrm{~m} / \mathrm{s})$ and myasthenic $(40.8 \pm 17.0 \mathrm{~m} / \mathrm{s})$ MU conduction velocities, this overlap being obvious if the plots of control (Fig. 6 of Kadrie and Brown, 1978) and myasthenic (Fig. 3) MU adjusted latencies to MU surface voltage are compared. Thus, in the ulnar nerve unlike the median nerve, there was no evidence of abnormalities in motor axon conduction velocity or in the MU size indicated by the surface voltage.

The central most important observation in this investigation was that decrements in the $p-p V$ of single MUs were frequently much larger than in the corresponding maximum compound potentials. This fact, itself, if not explicable by technical factors, suggested that not all MUs can be equally abnormal. The maximum compound potential represents, therefore, the summation of the responses of unequally involved MUs. Decrements

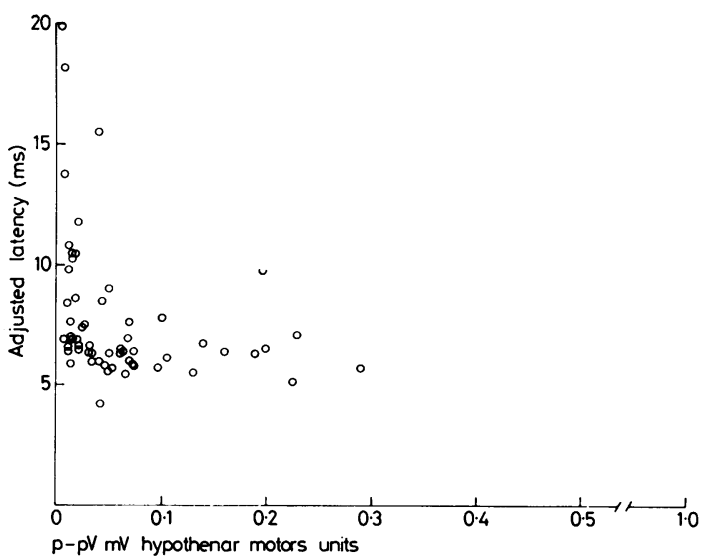

Fig. 3 Plot of the p-pV (in $m V$ ) of myasthenic hypothenar MUs against the respective latencies (in ms) adjusted for a distance of $200 \mathrm{~mm}$ from the motor point. This plot is nearly identical to that of control hypothenar MUs (Fig. 6 of Kadrie and Brown, 1978).

in individual p-pV were frequently much larger than $25 \%$, small MUs being much more abnormal than larger (Figs. 4, 5, 6).

In general, the maximum p-pV decrements were observed in the fifth MU potential evoked by a train of stimuli, though sometimes the maximum decrement was observed in the fourth or fifth potential. The maximum decrements were observed at stimulus intervals of 0.3 second, not 0.1 second, in most single MUs. Decrements of more than $50 \%$ in the $\mathrm{p}-\mathrm{pV}$ occurred only in small MUs less than $0.05 \mathrm{mV}$ p-p in surface voltage.

To what extent could the large p-pV decrements in small MUs be explained by the lower signal to noise ratios for such MUs? That this factor cannot explain the large decrements is evident in the observations that equivalent decrements were not observed at lower stimulus
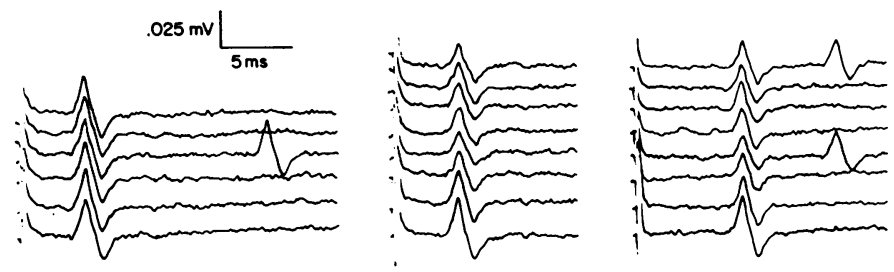

Fig. 4 Illustration of the changes in surface voltage of a small $M U(0.040$ $m V(p-p)$ evoked by trains of stimuli at 1.0 (left) and 0.3 second intervals (middle-right). The small $M U$ was isolated at the wrist (left-middle) and elbow (right) levels. Recurrent $F$ discharges occurred at both stimulation points. Note that in this $M U$ no significant decrement in $p-p V$ occurred at the stimulus interval of 1.0 second but at 0.3 second intervals, a $45 \%$ decrement occurred, maximum in the fourth $M U$ potential in the train at both levels of stimulation. 


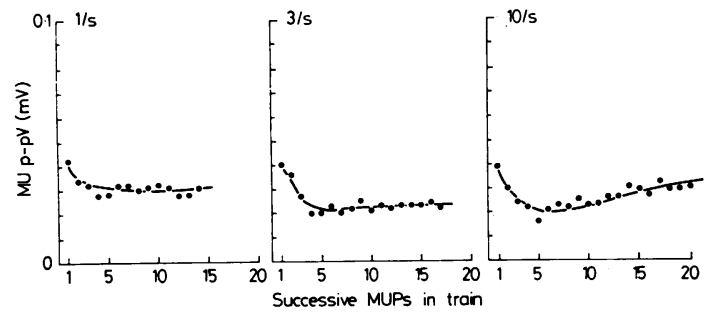

Fig. 5 Decrements in the p-pV (in $m V$ ) of a single myasthenic $M U, 0.04 \mathrm{mV}$ in $p-p V$, at stimulus intervals $1.0,0.3$, and 0.1 second. Note the maximum decrements were observed in the fourth or fifth $M U$ potential in the train. A decrement of $50 \%$ in the $p-p V$ occurred and should be compared with the more usual increments in $p-p V$ of comparable size control MUs (Fig. 9 of Kadrie and Brown, 1978).

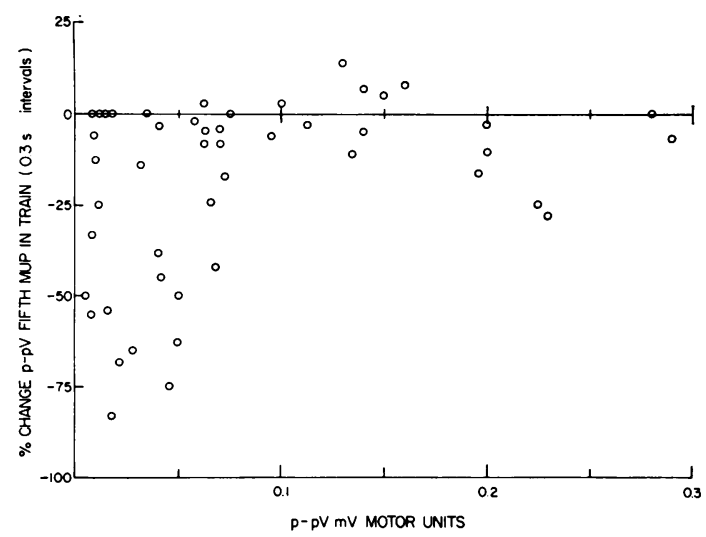

Fig. 6 Plot of the percentage change in the $p-p V$ of the fifth compared with the first $M U$ potentials in the train evoked by stimulation 0.3 second intervals. Note that all decrements over $30 \%$ occur in MUs less than $0.1 \mathrm{mV}$ in $p-p V$.

intervals or in control MUs of equivalent p-pV. Even if the p-pV decrements can be accepted is it reasonable to believe that these units correspond to the low force, low conduction velocity MUs in the MU population? For controls, at least, the surface voltage can be a reasonable index to the MU size (Milner-Brown and Stein, 1975; Kadrie, et al., 1976; Kadrie and Brown, 1978). The issue is complicated in myasthenic MUs because of the possibility that MUs could have lower than expected surface voltages if neuromuscular transmission failure occurred at a large enough fraction of the MU neuromuscular junctions. This factor was unlikely, however, in view of the nearly identical distributions of MU surface voltages and the relation between surface voltage and adjusted latencies in the hypothenar control and myasthenic
MU populations. Moreover, edrophonium chloride $10 \mathrm{mg}$ intravenously failed to increase the p-pV of the first MU potential evoked by stimulation regardless of whether large decrements in the $\mathrm{p}-\mathrm{pV}$ were observed or not. Therefore, it must be accepted that not only are the large decrements observed in the small MU real, but that the small surface voltage MU are likely at the low end of the MU force range.

The proportion of abnormal MUs varied from patient to patient. In the one myasthenic patient (O) having ocular and lid myasthenia only, all the MUs behaved normally. In the remaining patients the proportion of MUs tested that had $\mathrm{p}-\mathrm{pV}$ decrements of more than $5 \%$ varied from over $30 \%$ to $90 \%$. Very striking was the fact that the mean MU surface voltage decrement (32\%) was 6.5 times that corresponding $\mathrm{p}-\mathrm{pV}$ decrement for the maximum compound potentials. If the voltage decrements for individual MUs could be so large and the proportion of pathological MUs so high, it is reasonable to ask why much larger decrements were not observed in the maximum compound potentials. The explanations probably lie in the fact that MUs making the largest p-pV contributions to the maximum compound potential have the most normal neuromuscular transmission and the test MU population is probably biased numerically to the small MU because small MUs have a significantly lower threshold to electrical stimulation than larger units (Kadrie et al., 1976).

In 10 single MUs with abnormal p-pV decrements, edrophonium chloride partially reversed the decrement. Curiously, in one MU no decrement reversal occurred (Fig. 7). In this MU despite the striking decrement evoked by tetanic stimulation, quite contrary to the normal incremental response in control subjects (Kadrie and Brown, 1978), post-tetanic exhaustion was not observed. In fact, the decrement evoked by the test train of stimuli at 0.3 second intervals was much less after the tetanus than in the pretetanus trial (Fig. 8). Post-tetanic exhaustion was observed in the five other MUs tested and all had a pathological decrement at stimulus intervals of 0.3 second.

What was the relationship between changes in the surface voltage and at single neuromuscular junctions, the latter recorded by the single fibre EMG electrode? As with control subjects, it was technically difficult to record single muscle fibre spikes from the individual MUs excited using multiple point stimulation. All MUs with a detectable intramuscular potential had an obvious surface potential. In $20-50 \%$ of MUs with a surface voltage deflection, however, no corresponding intramuscular deflection could be recognised at amplifi- 


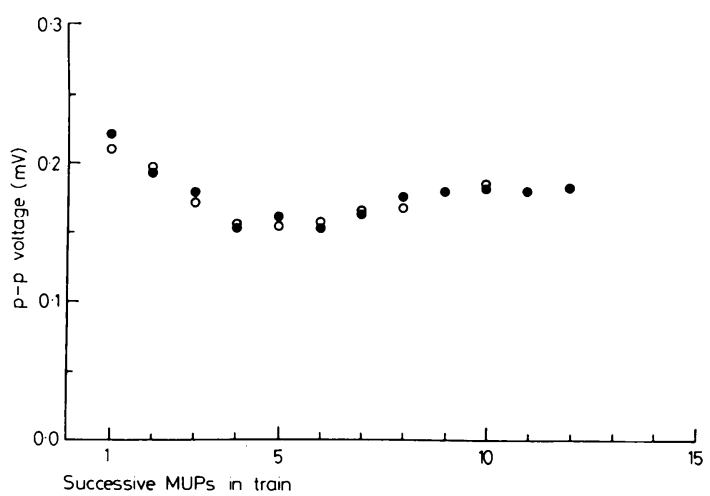

Fig. 7 Large $M U(0.210 \mathrm{mV} p-p)$. This $M U$ had the

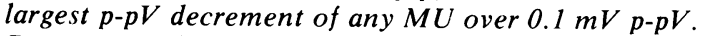
Decrement of $28 \%$ in $p-p V$ of fifth compared to the first MU potential evoked by a train of stimuli at 0.3 second intervals $(\bigcirc)$ and three minutes after $10 \mathrm{mg}$ edrophonium chloride intravenously $(\bigcirc)$. No significant changes in the $p-p V$ were observed at one minute intervals after edrophonium for 10 minutes.

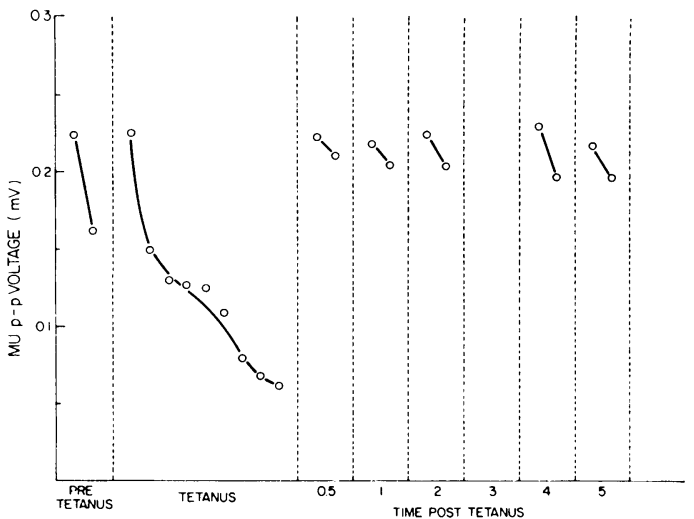

Fig. 8 Illustration of the changes observed in $p-p V$ (in $\mathrm{mV}$ ) of a single myasthenic MU that had a pathological decrement at stimulus intervals of 0.3 second (pretetanus). The fibre was stimulated at intervals of 0.02 second (every third MU potential plotted). At intervals post-tetanus (in minutes) test trains of stimuli at 0.3 second intervals were delivered. The p-pV of the first and fifth $M U$ potentials in the test trains are illustrated. Values at three minutes have been excluded because of electrical interference at that time. Post-tetanic exhaustion was not observed in this MU. At no time up to 10 minutes post-tetanus was more decrement observed than in the pretetanus trial.

cation gains of up to $0.01 \mathrm{mV}$ per division of the storage oscilloscope. The location of the single fibre EMG electrode was not changed in the course of the experiment from its initial placement in the hypothenar or thenar muscle complexes close to the endplate zones. Probably because of this, and the known restricted pick-up territory for this type of electrode (Rosenfalck, 1969), it is not surprising that not only were intramuscular voltage deflections not observed for all MUs clearly causing voltage deflection, but in only 10 of the total number of myasthenic MUs could single muscle fibre spikes be recorded. The changes in the latencies of muscle fibre action potentials in myasthenic MUs were identical to those previously reported by others (Stalberg and Ekstedt, 1973; Stalberg et al., 1974), and best illustrated by the MU in Fig. 9. In this MU, abnormal increases in the variation in latency of single muscle fibre action potentials and progressive latency increases to the point of block were observed. These variations in muscle fibre action potential latency were much larger than for controls (Stalberg and Ekstedt, 1973; Kadrie and Brown, 1978). In general the larger the surface voltage decrement, the larger the muscle fibre action potential latency variation and the more frequent the impulse block.

The MU in Fig. 9, was, however, unique. It was large in $\mathrm{p}-\mathrm{pV}$, and was the single exception to the

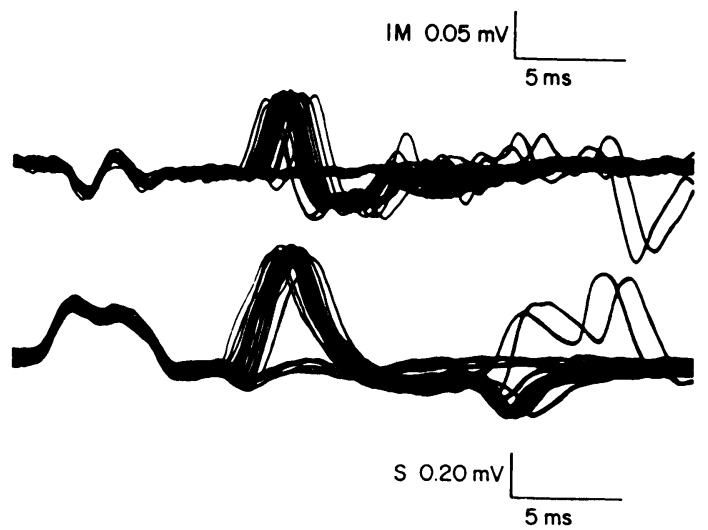

Fig. 9 Single $M U$ in patient $(P)$ illustrating a combination of intramuscular single fibre EMG (upper) and surface (lower) voltage recordings. Illustrated are the superimposed traces evoked by stimulation at 0.3 second intervals. Upper: there are three spikes recorded. The longest latency spike (right) fired two times only. The middle spike had a considerable variation in firing time $(>2 \mathrm{~ms})$, the latency progressively increasing to the point of block. The first spike had much less variation in latency $(<0.2 \mathrm{~ms})$. Lower: corresponding to the three intramuscular spikes were three deflections on the surface, each having a variation in latency nearly identical to that of the single fibres and blocking in parallel with the single fibre spikes. 
general rule that abnormalities in neuromuscular transmission were most severe in the small MU. Unlike other single MUs too, this one had the largest number (three) of single muscle fibre action potentials with the longest latency muscle fibre action potential blocking first and the mid-latency action potential blocking second. The first muscle fibre action potential had a much more normal variation in latency and no block. The most interesting observation in this MU, was that changes in the first, second and third muscle fibre action potentials were paralleled by changes in corresponding components in the surface recorded voltage. Such large surface voltage deflections could not have corresponded only to single muscle fibre action potentials. Even using averaging techniques, single muscle fibre action potentials cannot be recorded on the surface of the hypothenar or thenar muscles, at high gain. This meant that the intramuscular action potentials were only a part of much larger numbers of muscle fibres apparently divided into three distinct fractions, each behaving as a subunit in response to stimulus trains. Such a fractionation in the behaviour of myasthenic MUs has not been reported before but has been observed in response to curare in single healthy cat motor units (Locke and Henneman, 1960).

It is important to emphasise, as in the control subjects, that the stimulus intensities required to investigate single MUs in myasthenia gravis were one half or less compared to the intensities required to evoke maximum compound action potentials at the identical stimulation points. Stimulus trains even at stimulus intervals as low as 0.02 second were not uncomfortable, nor did they cause obvious movement artefact.

\section{Discussion}

The central observations in this investigation were (1) that neuromuscular transmission abnormalities are not present in all MUs, the proportion varying in patient to patient from 0 to $90 \%$; and (2) that decrements in the p-pV were larger for small (less than $0.050 \mathrm{mV}$ ) than for larger MUs, and frequently much larger than was evident in changes in the $\mathrm{p}$-pV for the maximum muscle compound action potentials at equivalent stimulus pulse intervals.

It is attractive to interpret these central observations in this investigation as evidence for neurogenic abnormalities in the disease. Certainly postmortem examinations of severely affected myasthenic subjects lend support to that contention (Fenichel and Shy, 1963; Brody and Engel,
1964; Fenichel, 1966; Brownell et al., 1972; Oosterhuis and Bethlem, 1973). In view, however, of the recent compelling evidence pointing to the postjunctional membrane as the primary target in myasthenia gravis and our own observations, to be reported later, that small MUs have the most abnormal neuromuscular transmission in other diseases, such as peripheral neuropathies and motor neurone disease, we have been led to an alternative hypothesis.

Perhaps small MUs have been the most abnormal in all diseases tested to date because they normally have lower margins for safe neuromuscular transmission than larger motor units. Such MUs would be more at risk of synaptic failure in diseases that attack at random the endplates, presynaptic axons, or motor neurones. The normal intrinsic properties of synaptic transmission could alone, therefore, explain the apparent selective liability of small MUs to neuromuscular transmission failure in a variety of diseases.

In man and animals, motor units have been divided according to certain physiological, structural, and histochemical properties (Close, 1972; Brandstater and Lambert, 1973; Kugelberg, 1973). Investigations have pointed to significant differences in the sizes and ultrastructure of the endplates between histochemically distinct muscle fibres (Gauthier and Padykula, 1966; Ogata et al., 1967; Ogata and Murata, 1969a, b; Padykula and Gauthier, 1970; Duchen, 1971; Santa and Engel, 1973). This evidence could support the hypothesis that neuromuscular transmission in larger white fibre MUs has a higher "margin of safety" for neuromuscular transmission because of the larger vesicle numbers in the presynaptic ending (Padykula and Gauthier, 1970), and a possibly larger concentration of postjunctional receptors in the white fibres (Santa and Engel, 1973). This hypothesis makes it unnecessary to implicate a primary pathological abnormality of the neuroneaxon component of the MU, and could lead to investigations into the relative safety factor for neuromuscular transmission in small and larger MUs.

This method for testing neuromuscular transmission in single MUs has certain advantages. There is little or no movement artefact, and the stimulus intensities required are much less than for supramaximal stimulation and, therefore, much more acceptable to patients. Furthermore, the decrements in the small MUs are much larger than changes in the maximum muscle compound potentials. Testing neuromuscular transmission at the level of the MU has been shown to be a much 
more sensitive indicator of abnormal neuromuscular transmission than supramaximal nerve stimulation tests. The latter, by its nature, must be less sensitive because it represents the summation of changes in abnormal and more normal MUs. It is questionable, however, if the method is likely to be a better test of neuromuscular transmission than other tests (Ozdemir and Young, 1971, 1976; Desmedt and Borenstein, 1976). The method, unfortunately, requires experience to isolate single MUs successfully by surface stimulation, and is not, therefore, practical for occasional users of the technique for diagnostic testing. To date the method has been used only for the hypothenar or thenar muscles, muscles not the most commonly or severely involved in myasthenia gravis (Simpson, 1974). It is possible that extension to more proximal and more commonly involved muscles could make it an even more sensitive test since tests using supramaximal stimulation are notably more sensitive when used to test facial or proximal limb muscles (Ozdemir and Young, 1971, 1976; Desmedt and Borenstein, 1976; Krarup, 1977a, b).

What of the relationship between the results of testing single MUs using multiple point stimulation and the results using the single fibre EMG electrode? The two tests were not specifically compared in this investigation but it is worth pointing out that both procedures probably test the same MU populations. Motor units investigated using the single fibre EMG electrode are usually among the first MUs recruited by muscle contraction. It is known that MUs are recruited from small to large by increases in the force of muscle contraction (Milner-Brown et al., 1973). It is likely, therefore, that most of the MUs investigated by the single fibre EMG electrode are the small, low force units, precisely the range of MUs recruited first by threshold electrical stimulation of the nerve (Kadrie et al., 1976) and observed in this investigation to have the most abnormal decrements in p-pV.

The combination of surface and single fibre EMG recording has the advantage of providing an index for the probable size and functional type of the MU recorded using the single fibre electrode. The restricted pick-up territory of the single fibreEMG electrode (Rosenfalck, 1969) limits the usefulness of the combination because satisfactory single muscle fibre action potentials can be recorded from less than $10 \%$ of the MUs. Even adjustments of the intramuscular electrode position marginally improve the chances of recording single muscle fibre action potentials and increases substantially the discomfort to the patient. It is clear, however, that MUs with large p-pV decrements measured on the surface, have pathological variations in muscle fibre action potential latency and impulse block occurs frequently. All this was evident in the motor unit chosen for illustration. Distinctly unusual, however, were the observations that neuromuscular transmission could fail in large subfractions of the MU, and not in the usual graded manner observed in all the other abnormal MUs tested. The fact that impulse block occurred at stimulus pulse intervals of more than one second made impulse block at a major axon branch point unlikely (Desmedt, 1973). Possibly for reasons unknown, all the neuromuscular junctions failed more or less together in large MU fractions. This has not been observed before in myasthenia gravis but similar "all or nothing"-like failures in large fractions of single cat MUs have been observed in response to curare (Locke and Henneman, 1960).

In the hypothenar muscle complex the single MU conduction velocities and distribution of MU p-pVs were not significantly different from controls. In the median nerve territory, however, the mean MU potential $\mathrm{p}-\mathrm{pV}$ was larger and the single MU conduction velocity lower than compared to control subjects. The reason for this discrepancy between the median and ulnar nerve territories is not obvious but a possible neurogenic factor, at least in the median nerve territory, might be suggested. The nature of this factor or factors is not known. Certainly there was no evidence of spontaneous fibrillation potentials or positive sharp waves in the thenar muscle complex.

Interesting observations that require more extensive investigation were the occasional paradoxes in single MUs. Examples included the MU in which no decrement reversal occurred in response to edrophonium chloride. This had a very pathological decrement in response to repetitive stimulation but no post-tetanic exhaustion. The latter has been claimed to be a specific and very sensitive index of the myasthenic neuromuscular transmission abnormality (Desmedt, 1973). Evidently the functional abnormalities revealed by tetanic stimulation and repetitive stimulation at lower frequencies do not necessarily go hand in hand in the same MU. Supramaximal stimulation investigative methods preclude the possibility of looking for such lack of parallelism between functional abnormalities in MUs. The fact that the distinctive types of functional abnormality may not occur together in the same MU certainly suggests that the mechanisms differ and underlines the importance of further investigations into the cause of these functional abnormalities at the level of the MU and individual neuromuscular junctions. 
We wish to thank the patients who consented to these investigations, Mrs N. McGregor for typing the manuscript, Mr G. Moogk for the illustrations, and $\mathrm{Mr} \mathrm{S}$. Yates for his technical assistance.

\section{References}

Ballantyne, J. P., and Hansen, S. (1974). Computer method for the analysis of evoked motor unit potentials. 1. Control subjects and patients with myasthenia gravis. Journal of Neurology, Neurosurgery, and Psychiatry, 37, 1187-1194.

Brandstater, M. E., and Lambert, E. H. (1973). Motor unit anatomy type and spatial arrangement of muscle fibres. In New Developments in Electromyography and Clinical Neurophysiology. Vol. 1, pp. 14-22. Edited by J. E. Desmedt, Karger: Basel.

Brody, I. A., and Engel, W. K. (1964). Denervation of muscle in myasthenia gravis. Archives of Neurology (Chicago), 11, 350-354.

Brown, W. F., and Milner-Brown, H. S. (1976). Some electrical properties of motor units and their effects on the methods of estimating motor numbers. Journal of Neurology, Neurosurgery, and Psychiatry, 39, 249-257.

Brownell, B., Oppenheimer, D. R., and Spalding, J. M. K. (1972). Neurogenic muscle atrophy in myasthenia gravis. Journal of Neurology, Neurosurgery, and Psychiatry, 35, 311-322.

Close, R. I. (1972). Dynamic properties of mammalian skeletal muscles. Physiological Reviews, 52, 129 185.

Desmedt, J. E. (1973). The neuromuscular disorder in myasthenia gravis. I. Electrical and Mechanical response to nerve stimulation in hand muscles. II. Presynaptic cholinergic metabolism, myastheniclike syndromes and a hypothesis. In New Developments in Electromyography and Clinical Neurophysiology. Vol 1, pp. 241-342. Edited by J. E. Desmedt. Karger: Basel.

Desmedt, J. E., and Borenstein, S. (1970). The testing of neuromuscular transmission. In Handbook of Neurology. Vol. 7, pp. 104-115. Edited by P. J. Vinken and G. W. Bruyn. North Holland: Amsterdam.

Desmedt, J. E., and Borenstein, S. (1976). Diagnosis of myasthenia gravis by nerve stimulation. Annals of the New York Academy of Sciences, 274, 174188.

Duchen, L. W. (1971). An electron microscopic comparison of motor end-plates of slow and fast skeletal muscle fibers of the mouse. Journal of the Neurological Sciences, 14, 37-45.

Elmqvist, D., Mattsson, C., Heilbronn, E., Lundh, H., and Libelius, R. (1977). Acetylcholine receptor protein. Neuromuscular transmission in immunized rabbits. Archives of Neurology (Chicago), 34, 7-11.

Engel, A. G., Tsujihata, M., Lambert. E. H., Lindstrom, J. M., and Lennon, V. A. (1976). Experimental autoimmune myasthenia gravis: a sequential and quantitative study of the neuromuscular junction ultrastructure and electrophysiological correlations. Journal of Neuropathology and Experimental Neurology, 35, 569-587.

Fenichel, G. M. (1966). Muscle lesions in myasthenia gravis. Annals of the New York Academy of Sciences, 135, 60-67.

Fenichel, G. M., and Shy, M. (1963). Muscle biopsy experience in myasthenia gravis. Archives of Neurology (Chicago), 9, 237-243.

Gauthier, G. F., and Padykula, H. A. (1966). Cytological studies of fiber types in skeletal muscle. Journal of Cell Biology, 28, 333-354.

Kadrie, H. A., and Brown, W. F. (1978). Neuromuscular transmission in single human motor units. Journal of Neurology, Neurosurgery, and Psychiatry, 41, $193-204$.

Kadrie, H. A., Yates, S. K., Milner-Brown, H. S., and Brown, W. F. (1976). Multiple point stimulation of ulnar and median nerves. Journal of Neurology, Neurosurgery, and Psychiatry, 39, 973-985.

Krarup, C. (1977a). Electrical and mechanical responses in the platysma and in the adductor pollicis muscle: in normal subjects. Journal of Neurology, Neurosurgery, and Psychiatry, 40, 234240.

Krarup, C. (1977b). Electrical and mechanical responses in the platysma and in the adductor pollicis muscle: in patients with myasthenia gravis. Journal of Neurology, Neurosurgery, and Psychiatry, 40, 241-249.

Kugelberg, E. (1973). Properties of the rat hind-limb motor units. In New Developments in Electromyography and Clinical Neurophysiology. Vol. 1, pp. 2-13. Edited by J. E. Desmedt. Karger: Basel.

Lambert, E. H., Rooke, E. D., Eaton, L. M., and Hodgson, C. H. (1961). Myasthenic syndrome occasionally associated with bronchial neoplasm. Neurophysiologic studies. In Myasthenia Gravis, pp. 362-410. Edited by H. R. Viets. Charles C. Thomas: Springfield, Illinois.

Locke, S., and Henneman, E. (1960). Fractionation of motor units by curare. Experimental Neurology, 2, 638-651.

Milner-Brown, H. S., and Brown, W. F. (1976). New methods of estimating the number of motor units in a muscle. Journal of Neurology, Neurosurgery, and Psychiatry, 39, 258-265.

Milner-Brown, H. S., and Stein, R. B. (1975). The relation between the surface electromyogram and muscular force. Journal of Physiology, 246, 549569.

Milner-Brown, H. S., Stein, R. B., and Yemm, R. (1973). The orderly recruitment of human motor units during voluntary isometric contractions. Journal of Physiology, 230, 359-370.

McComas, A. J., Sica, R. E. P., and Brown, J. C. (1971). Myasthenia gravis: evidence for a central defect. Journal of the Neurological Sciences, 13, 107-113.

Ogata, T., Hondo, T., and Seito, T. (1967). An electron microscopic study on differences in the fine structure of motor end-plates in red, white and intermediate fibres of rat intercostal muscle. A pre- 
liminary study. Acta Medica Okayama, 21, 327338.

Ogata, T., and Murata, F. (1969a). Fine structure of motor end-plate in red, white and intermediate fibres of mammalian fast muscle. Tohoku Journal of Experimental Medicine, 98, 107-115.

Ogata, T., and Murata, F. (1969b). Cytological features of three fiber types in human striated muscle. Tohoku Journal of Experimental Medicine, 99, 225-245.

Oosterhuis, H., and Bethlem, J. (1973). Neurogenic muscle involvement in myasthenia gravis. A clinical and histopathological study. Journal of Neurology, Neurosurgery, and Psychiatry, 36, 244-254.

Ozdemir, C., and Young, R. R. (1971). Electrical testing in myasthenia gravis. Annals of the New York Academy of Sciences, 183, 287-302.

Ozdemir, C., and Young, R. R. (1976). The results to be expected from electrical testing in the diagnosis of myasthenia gravis. Annals of the New York Academy of Sciences, 203-222.

Padykula, H. A., and Gauthier, G. F. (1970). The ultrastructure of the neuromuscular junction of mammalian red, white and intermediate skeletal muscle fibres. Journal of Cell Biology, 46, 27-41.

Rosenfalck, P. (1969). Intra- and Extracellular Potential Fields of Active Nerve and Muscle Fibres. Akademisk Forlag: Copenhagen.

Santa, T., and Engel, A. G. (1973). Histometric analysis of neuromuscular junction ultrastructure in rat red, white and intermediate muscle fibres. In New Developments in Electromyography and Clinical
Neurophysiology. Vol. 1, pp. 41-54. Edited by J. E. Desmedt. Karger: Basel.

Satyamurti, S., Drachman, D. B., and Slone, F. (1975). Blockade of acetylcholine receptors: a model of myasthenia gravis. Science, 187, 955-957.

Simpson, J. A. (1974). Myasthenia gravis and myasthenic syndromes. In Disorders of Voluntary Muscle. Edited by J. N. Walton. Third edition, pp. 653-692. Churchill Livingstone: Edinburgh and London.

Slomic, A., Rosenfalck, P., and Buchthal, F. (1968). Electrical and mechanical responses of normal and myasthenic muscle with particular reference to the staircase phenomenon. Brain Research, 10, 1-78. (special issue).

Stalberg, E., and Ekstedt, J. (1973). Single fiber EMG and microphysiology of the motor unit in normal and diseased human muscle. In New Developments in Electromyography and Clinical Neurophysiology. Vol. 1, pp. 113-129. Edited by J. E. Desmedt, Karger: Basel.

Stalberg, E., Ekstedt, J., and Broman, A. (1974). Neuromuscular transmission in myasthenia gravis studied with single fibre electromyography. Journal of Neurology, Neurosurgery, and Psychiatry, 37, 540-547.

Thornell, L. E., Sjostrum, M., Mattsson, C. H., and Heilbronn, F. (1976). Morphological observations on motor end-plates in rabbits with experimental myasthenia. Journal of the Neurological Sciences, 29, 389-410. 